\title{
Complete genome sequence of Mesorhizobium ciceri bv. biserrulae type strain (WSM1271')
}

\author{
Kemanthi Nandasena ${ }^{1}$, Ron Yates ${ }^{1,5}$, Ravi Tiwari ${ }^{1}$, Graham O'Hara ${ }^{1}$, John Howieson ${ }^{1}$, Mo- \\ hamed Ninawi ${ }^{1}$, Olga Chertkov ${ }^{2}$, Chris Detter ${ }^{2}$, Roxanne Tapia ${ }^{2}$, Shunseng Han ${ }^{2}$, Tanja \\ Woyke $^{3}$, Sam Pitluck ${ }^{3}$, Matt Nolan ${ }^{3}$, Miriam Land ${ }^{4}$, Konstantinos Liolios ${ }^{3}$, Amrita Pati ${ }^{3}$, Alex \\ Copeland ${ }^{3}$, Nikos Kyrpides ${ }^{3}$, Natalia Ivanova ${ }^{3}$, Lynne Goodwin ${ }^{3}$, Uma Meenakshi ${ }^{1}$, \& Wayne \\ Reeve $^{* 1}$. \\ ${ }^{1}$ Centre for Rhizobium Studies, Murdoch University, Western Australia, Australia \\ ${ }^{2}$ Los Alamos National Laboratory, Bioscience Division, Los Alamos, New Mexico, USA \\ ${ }^{3}$ DOE Joint Genome Institute, Walnut Creek, California, USA \\ ${ }^{4}$ Oak Ridge National Laboratory, Oak Ridge, Tennessee, USA \\ ${ }^{5}$ Department of Agriculture and Food, Western Australia, Australia
}

*Correspondence: Wayne Reeve (W.Reeve@murdoch.edu.au)

Keywords: root-nodule bacteria, nitrog en fixation, evolution, lateral gene transfer, integ rative and conjug ative elements, symbiosis, Alphaproteobacteria

\begin{abstract}
Mesorhizobium ciceri bv. biserrulae strain WSM1271 was isolated from root nodules of the pasture legume $B$ iserrula pelecinus g rowing in the Mediterranean basin. Previous studies have shown this aerobic, motile, Gram negative, non-spore-forming rod preferably nodulates $B$. pelecinus - a legume with many beneficial agronomic attributes for sustainable agriculture in Australia. We describe the genome of Mesorhizobium ciceri bv. biserrulae strain WSM12 71 consisting of a 6,264,489 bp chromosome and a 425,539 bp plasmid that together encode 6,470 protein-coding genes and 61 RNAonly encoding genes.
\end{abstract}

\section{Introduction}

The productivity of sustainable agriculture around the world is heavily dependent on the provision of bioavailable nitrogen $(\mathrm{N})$ [1]. The demand for $\mathrm{N}$ by non-leguminous and leguminous plants can be supplied by the application of chemically synthesized nitrogenous fertilizer onto crops and pastures. However, the production of fertilizer is costly and requires the burning of fossil fuels in the manufacturing process which increases greenhouse gas emissions. Furthermore, high application rates of fertilizer can contaminate ecosystems and waterways, and result in leaching into the environment.

In contrast, the demand for $\mathrm{N}$ by leguminous plants can be sustainably met through the biological process of $\mathrm{N}$ fixation that occurs following the successful formation of an effective symbiosis. This symbiotic nitrogen fixation (SNF) process can account for approximately $70 \%$ of the bioavailable nitrogen supplied to legumes [1].

One legume that has many beneficial agronomic attributes is Biserrula pelecinus L., which is an annual herbaceous legume native to the Mediterranean basin that was introduced into Australian soil in 1994 [2]. The beneficial agronomic attributes of this legume include drought tolerance, hard seed production, easy harvesting characteristics, insect tolerance and most importantly, a capacity to grow well in the acidic duplex soils of Australia [2,3]. This monospecific legume specifically forms an effective nitrogen fixing symbiosis with the root nodule bacterium Mesorhizobium ciceri bv. biserrulae type strain WSM1271 ${ }^{\mathrm{T}}$ (= LMG23838 = HAMBI2942) [4,5]. Australian indigenous rhizobial populations were found to be incapable of nodulating B. pelecinus L [2]. However, within six years of the introduction of the inoculant into Australia, the in situ evolution of a diverse range of competitive strains capable of nodulating $B$. pelecinus $\mathrm{L}$. compromised optimal $\mathrm{N}_{2}$-fixation with this host. This rapid emergence of less effective strains threatens the establishment of this legume species in the Australian agricultural setting. The sub-optimal strains appear to have evolved from indigenous mesorhizobia that acquired the island of genes associated with symbiosis from the original inoculant, WSM1271T, following a horizontal gene transfer event [6]. 
In this report, a summary classification and a set of general features for $M$. ciceri bv. biserrulae strain WSM1271 ${ }^{\mathrm{T}}$ are presented together with the description of the complete genome sequence and its annotation.

\section{Classification and features}

M. ciceri strain WSM1271 ${ }^{\mathrm{T}}$ is a motile, Gramnegative, non-spore-forming rod (Figure 1 and Figure 2) in the order Rhizobiales of the class Alphaproteobacteria. They are moderately fast growing, forming 2-4 mm diameter colonies within 3-4 days, and have a mean generation time of 4$6 \mathrm{~h}$ when grown in half Lupin Agar (1/2LA) broth [7] at $28{ }^{\circ} \mathrm{C}$. Colonies on $1 / 2$ LA are white-opaque, slightly domed, moderately mucoid with smooth margins (Figure 3).

The organism tolerates a pH range between 5.5 and 9.0. Carbon source utilization and fatty acid profiles have been described before [6]. Minimum Information about the Genome Sequence (MIGS) is provided in Table 1.

Figure 4 shows the phylogenetic neighborhood of $M$. ciceri bv. biserrulae strain WSM1271 ${ }^{\mathrm{T}}$ in a $16 \mathrm{~S}$ rRNA sequence based tree. This strain clustered in a tight group, which included $M$. australicum, $M$. ciceri, $M$. loti and $M$. shangrilense and had $>99 \%$ sequence identity with all four type strains. Our polyphasic taxonomic study indicates that WSM $1271^{\mathrm{T}}$ is a new biovar of nodulating bacteria [5].

\section{Symbiotaxonomy}

M. ciceri bv. biserrulae strain WSM1271 ${ }^{\mathrm{T}}$ has an extremely narrow legume host range for symbiosis only forming highly effective nitrogen-fixing root nodules on Biserrula pelecinus. L. This strain also nodulates the closely related species Astragalus membranaceus but does not nodulate 21 other legume species nodulated by Mesorhizobium spp [5]. The high degree of specificity in the symbiotic relationships of this strain is representative of root nodule bacteria isolated from B. pelecinus L. growing in undisturbed landscapes in the Mediterranean basin, and is an important example of a highly specific legume hostroot nodule bacteria relationship in an annual herbaceous legume used as a forage species in agriculture.

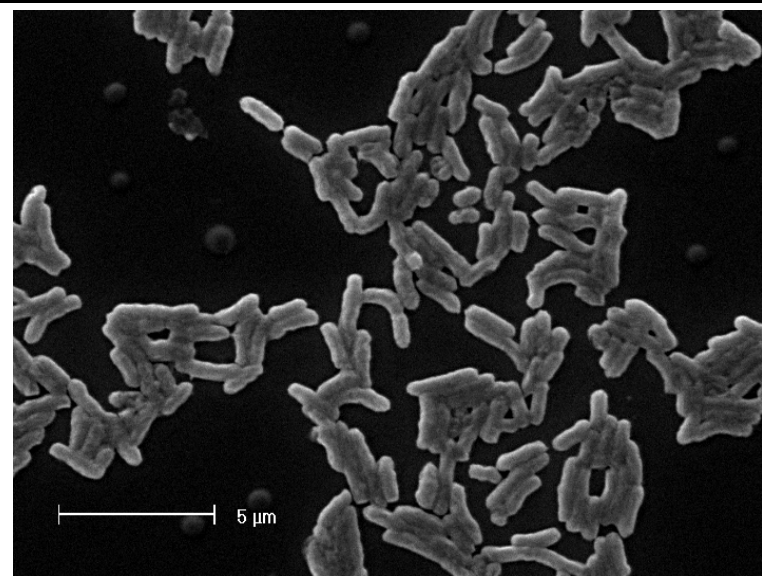

Figure 1. Image of Mesorhizobium ciceri bv. biserrulae strain WSM1271 using scanning electron microscopy.

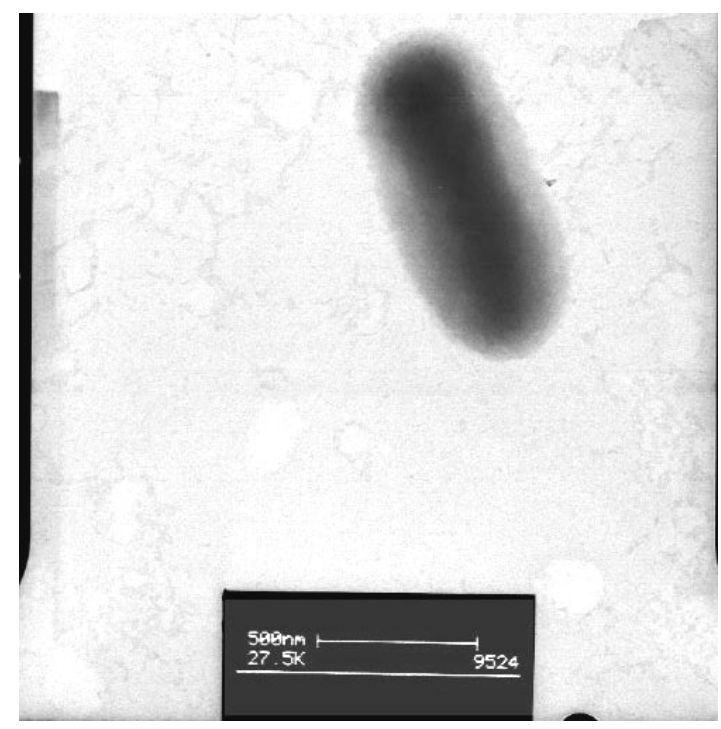

Figure 2. Image of Mesorhizobium ciceri bv. biserrulae strain WSM $1271^{\top}$ using transmission electron microscopy.

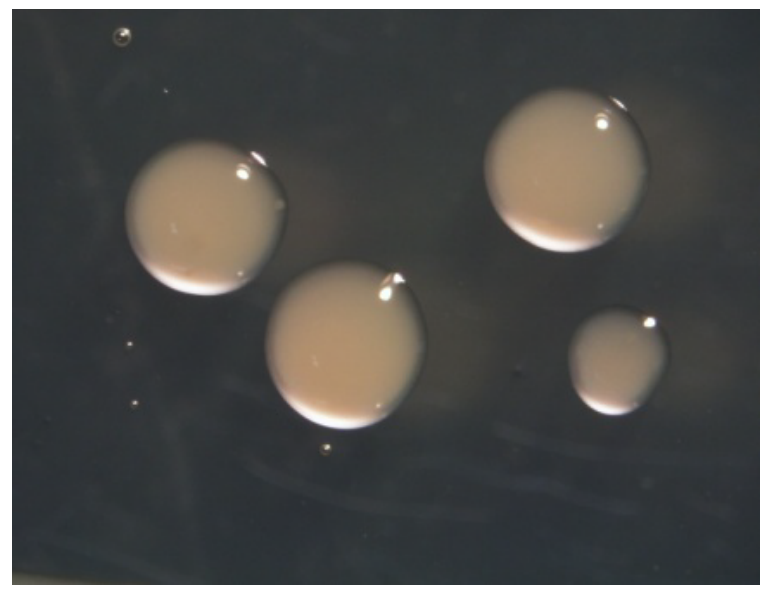

Figure 3. Image of Mesorhizobium ciceri bv. biserrulae strain WSM $1271^{\top}$ using the appearance of colony morphology on solid media. 
Table 1. Classification and features of Mesorhizobium ciceribv. biserrulae strain WSM $1271^{\top}$ according to the MIGS recommendations $[8,9]$.

\begin{tabular}{|c|c|c|c|}
\hline MIGS ID & Property & Term & Evidence code \\
\hline & \multirow{7}{*}{ Current classification } & Domain Bacteria & TAS [9] \\
\hline & & Phylum Proteobacteria & TAS [10] \\
\hline & & Class Alphaproteobacteria & TAS $[11,12]$ \\
\hline & & Order Rhizobiales & TAS $[11,13]$ \\
\hline & & Family Phyllobacteriaceae & TAS $[11,14]$ \\
\hline & & Genus Mesorhizobium & TAS [15] \\
\hline & & Species Mesorhizobium ciceri bv biserrulae & TAS [15] \\
\hline & Gram stain & Negative & TAS [6] \\
\hline & Cell shape & Rod & TAS [6] \\
\hline & Motility & Motile & TAS [6] \\
\hline & Sporulation & Non-sporulating & TAS [16] \\
\hline & Temperature range & Mesophile & TAS [16] \\
\hline & Optimum temperature & $28^{\circ} \mathrm{C}$ & TAS [6] \\
\hline & Salinity & Unknown & NAS \\
\hline \multirow[t]{3}{*}{ MIGS-22 } & Oxygen requirement & Aerobic & TAS [16] \\
\hline & Carbon source & Arabinose, 8 entibiose, glucose, mannitol \& melibiose & TAS [6] \\
\hline & Energy source & Chemoorg anotroph & TAS [16] \\
\hline MIGS-6 & Habitat & Soil, root nodule, host & TAS [6] \\
\hline MIGS-15 & Biotic relationship & Free living, Symbiotic & TAS [6] \\
\hline \multirow[t]{3}{*}{ MIGS-14 } & Pathog enicity & None & NAS \\
\hline & Biosafety level & 1 & TAS [17] \\
\hline & Isolation & Root nodule & TAS $[5,6]$ \\
\hline MIGS-4 & Geog raphic location & $5 \mathrm{~km}$ before Bottida, Sardinia & TAS $[2,5]$ \\
\hline MIGS-5 & Nodule collection date & April 1993 & TAS [4] \\
\hline MIGS-4.1 & Long itude & 9.012008 & NAS \\
\hline MIGS-4.2 & Latitude & 40.382709 & NAS \\
\hline MIGS-4.3 & Depth & $10 \mathrm{~cm}$ & NAS \\
\hline MIGS-4.4 & Altitude & $295 \mathrm{~m}$ & TAS [5] \\
\hline
\end{tabular}

Evidence codes - TAS: Traceable Author Statement (i.e., a direct report exists in the literature); NAS: Nontraceable Author Statement (i.e., not directly observed for the living, isolated sample, but based on a generally accepted property for the species, or anecdotal evidence). Evidence codes are from the Gene Ontology project [18]. 


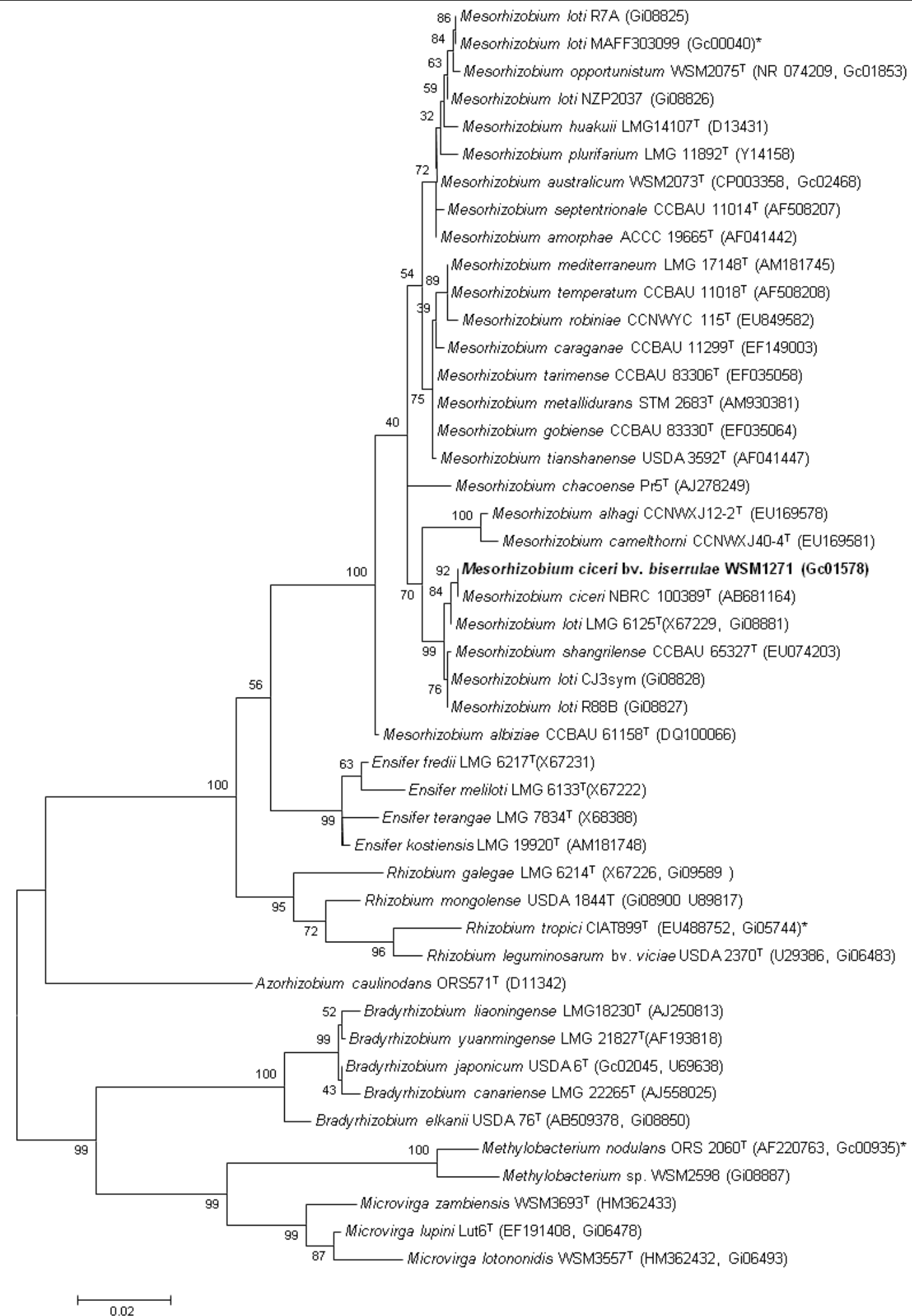

Figure 4. Phylogenetic tree showing the relationships of Mesorhizobium ciceri bv. biserrulae WSM1271. (shown in bold print) with root nodule bacteria in the order Rhizobiales based on aligned sequences of the 16S rRNA gene (1,290 bp internal region). All sites were informative and there were no gap-containing sites. Phylogenetic analyses were performed using MEGA [19]. The tree was built using the Maximum-Likelihood method with the General Time Reversible model. Bootstrap analysis [20] was performed with 500 replicates to assess the support of the clusters. Type strains are indicated with a superscript T. Brackets after the strain name contain a DNA database accession number and/or a GOLD ID (beginning with the prefix G) for a sequencing project registered in GOLD [21]. Published genomes are indicated with an asterisk. 


\section{Genome sequencing and annotation}

\section{Genome project history}

The Joint Genome Institute (JGI) operated by US Department of Energy (DOE) sequenced, finished and annotated WSM1271 as part of the Community Sequencing Program (CSP). The genome project is deposited in the Genomes OnLine Database [21]. The finished genome sequence is in GenBank. The CSP selects projects on the basis of environmental and agricultural relevance to issues in global carbon cycling, alternative energy production, and bi- ogeochemical importance. Table 2 summarizes the project information.

\section{Growth conditions and DNA isolation}

M. ciceri bv. biserrulae strain WSM1271 ${ }^{\mathrm{T}}$ was grown to mid logarithmic phase in TY rich medium [22] on a gyratory shaker at $28{ }^{\circ} \mathrm{C}$. DNA was isolated from $60 \mathrm{~mL}$ of cells using a CTAB (Cetyl trimethyl ammonium bromide) bacterial genomic DNA isolation method [23].

Table 2. Genome sequencing project information for Mesorhizobium ciceri bv. biserrulae strain WSM1271

\begin{tabular}{lll}
\hline MIGS ID & Property & Term \\
\hline MIGS-31 & Finishing quality & Finished \\
MIGS-28 & Libraries used & $\begin{array}{l}\text { Illumina GAii shotg un library, } \\
\text { 454 Titanium standard library and paired end 454 libraries }\end{array}$ \\
MIGS-29 & Sequencing platforms & Illumina and 454 technologies \\
MIGS-31.2 Sequencing coverage & $454(26.8 x)$ and Illumina (124x) \\
MIGS-30 & Assemblers & Newbler, version 2.3 and Velvet version 0.7.63, PHRAP and CONSED \\
MIGS-32 & Gene calling method & Prodigal, GenePrimp \\
& Genbank ID & CP002447, CP002448 \\
& Genbank Date of Release & November 10, 2012 \\
& GOLD ID & Gc01578 \\
& NCBI project ID & 48991 \\
& Database: IMG & 649633066 \\
& Project relevance & Symbiotic nitrogen fixation, ag riculture \\
\hline
\end{tabular}

\section{Genome sequencing and assembly}

The Joint Genome Institute (JGI) generated the draft genome of $M$. ciceri bv. biserrulae WSM $1271^{\mathrm{T}}$ using a combination of Illumina [24] and 454 technologies [25]. The sequencing of an Illumina GAii shotgun library generated 23,461,369 reads totaling $844.6 \mathrm{Mb}$, a 454 Titanium standard library which generated 277,881 reads and a paired end 454 libraries with average insert size of $1.137+/-2.842 \mathrm{~Kb}$ and $4.378+/-$ $1.094 \mathrm{~kb}$ which generated 40,653 and 130,843 reads totaling $244.0 \mathrm{Mb}$ of 454 data. All general aspects of library construction and sequencing performed at the JGI can be found at the JGI website [23]. The initial draft assembly contained 32 contigs in 2 scaffolds. The 454 Titanium standard data and the 454 paired end data were assembled together with Newbler, version 2.3. The Newbler consensus sequences were computationally shredded into $2 \mathrm{~Kb}$ overlapping fake reads (shreds). Illumina sequencing data was assembled with VELVET, version 0.7.63 [26], and the consensus sequences were computationally shredded into $1.5 \mathrm{~Kb}$ overlapping fake reads (shreds). We integrated the 454 Newbler consensus shreds, the Illumina VELVET consensus shreds and the read pairs in the 454 paired end library using parallel phrap, version SPS - 4.24 (High Performance Software, LLC). The software Consed [27-29] was used in the following finishing process. Illumina data was used to correct potential base errors and increase consensus quality using the software Polisher developed at JGI (Alla Lapidus, unpublished). Possible mis-assemblies were corrected using gapResolution (Cliff Han, unpublished), 
Dupfinisher [30], or sequencing cloned bridging PCR fragments with subcloning. Gaps between contigs were closed by editing in Consed, by PCR and by Bubble PCR (J-F Cheng, unpublished) primer walks. A total of 49 additional reactions were necessary to close gaps and to raise the quality of the finished sequence. The total size of the genome is $6,890,027 \mathrm{bp}$ and the final assembly is based on $112.0 \mathrm{Mb}$ of 454 draft data which provides an average $26.8 \times$ coverage of the genome and $832.1 \mathrm{Mb}$ of Illumina draft data which provides an average $124 \times$ coverage of the genome.

\section{Genome annotation}

Genes were identified using Prodigal [31] as part of the Oak Ridge National Laboratory genome annotation pipeline, followed by a round of manual curation using the JGI GenePrimp pipeline [32]. The predicted CDSs were translated and used to search the National Center for Biotechnology Information (NCBI) non-redundant database, UniProt, TIGRFam, Pfam, PRIAM, KEGG, COG, and
InterPro databases. These data sources were combined to assert a product description for each predicted protein. Non-coding genes and miscellaneous features were predicted using tRNAscanSE [33], RNAMMer [34], Rfam [35], TMHMM [36], and SignalP [37]. Additional gene prediction analyses and functional annotation were performed within the Integrated Microbial Genomes (IMGER) platform [38].

\section{Genome properties}

The genome is $6,690,028$ bp long with a $62.56 \%$ GC content (Table 3) and comprises a single chromosome and a single plasmid. From a total of 6,531 genes, 6,470 were protein encoding and 61 RNA only encoding genes. Within the genome, 206 pseudogenes were also identified. The majority of genes $(70.74 \%)$ were assigned a putative function while the remaining genes were annotated as hypothetical. The distribution of genes into COGs functional categories is presented in Table 4, and Figures 5,6 and 7.

Table 3. Genome Statistics for Mesorhizobium ciceri bv. biserrulae strain WSM1271'.

\begin{tabular}{lrr}
\hline Attribute & Value & \% of Total \\
\hline Genome size (bp) & $6,690,028$ & 100.00 \\
DNA coding region (bp) & $5,791,860$ & 86.57 \\
DNA G+C content (bp) & $4,185,397$ & 62.56 \\
Number of replicons & 1 & \\
Extrachromosomal elements & 6,531 & 100.00 \\
Total genes & 61 & 0.93 \\
RNA genes & 6,470 & 99.07 \\
Protein-coding genes & 4,620 & 70.74 \\
Genes with function prediction & 5174 & 79.22 \\
Genes assig ned to COGs & 5398 & 82.65 \\
Genes assig ned Pfam domains & 597 & 9.14 \\
Genes with signal peptides & 1528 & 23.40 \\
Genes with transmembrane helices & & \\
\hline
\end{tabular}




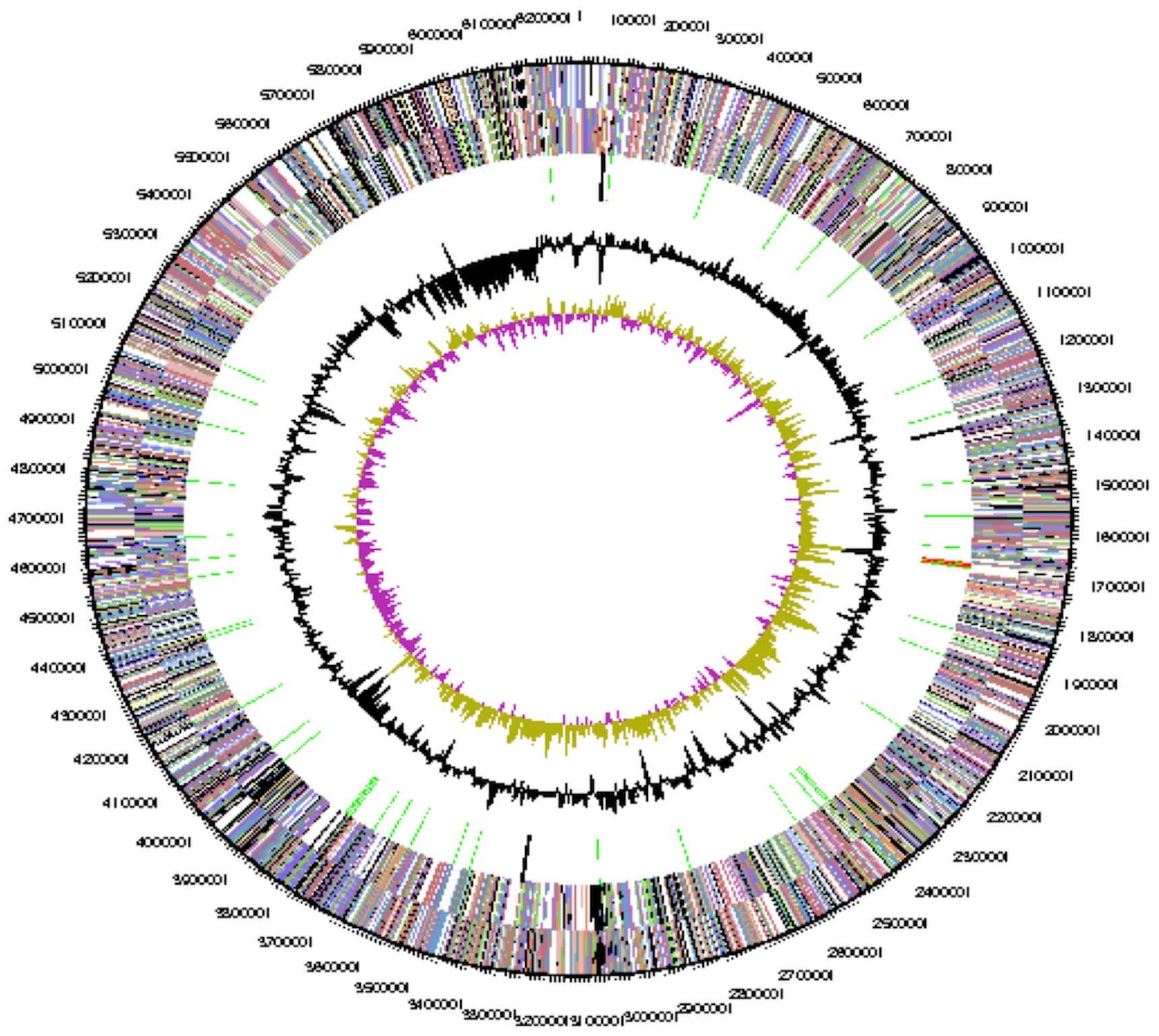

Figure 5. Graphical circular map of the chromosome. From outside to the center: Genes on forward strand (color by COG categ ories as denoted by the IMG platform), Genes on reverse strand (color by COG categories), RNA genes (tRNAs g reen, sRNAs red, other RNAs black), GC content, GC skew. 


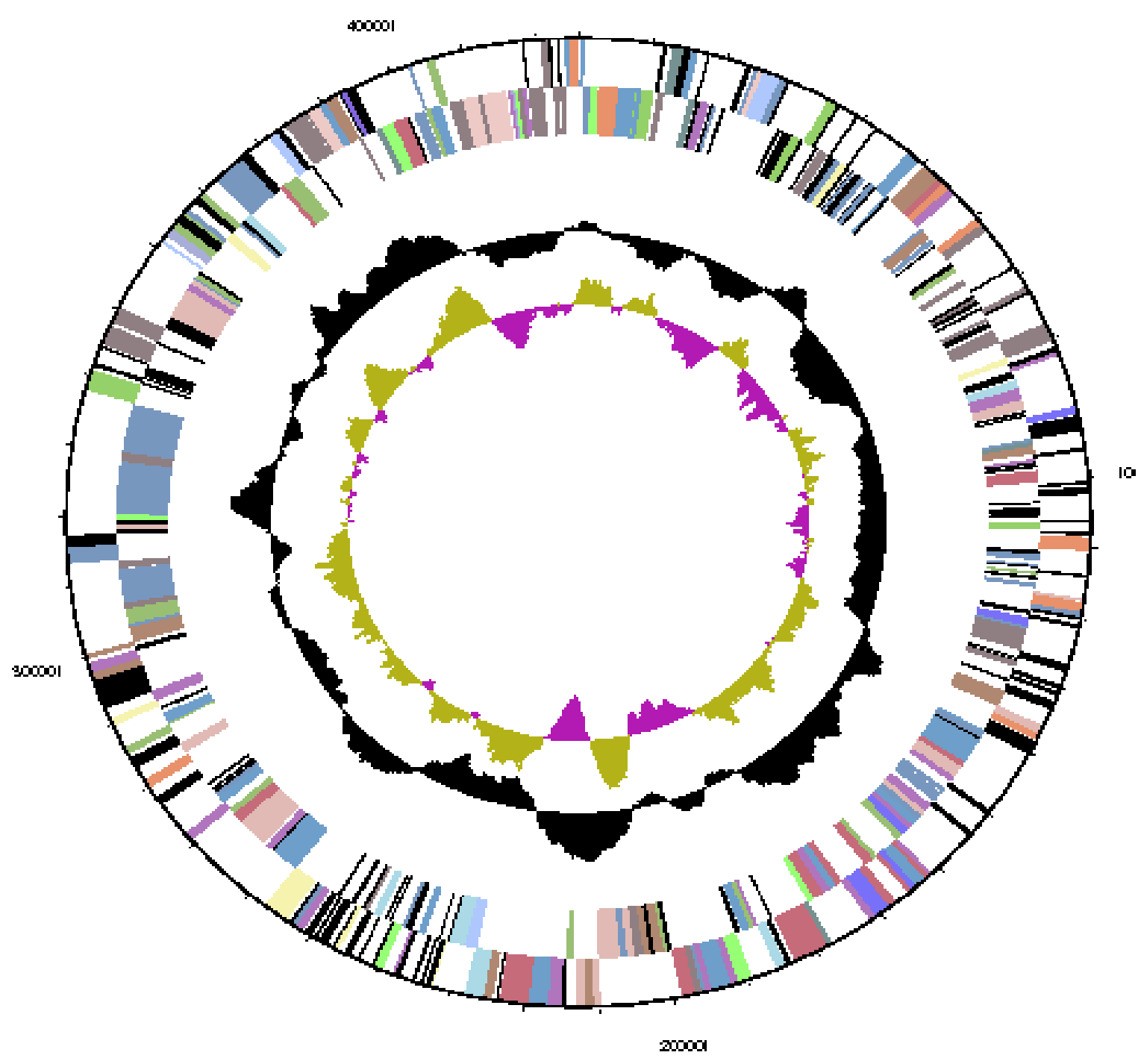

Figure 6. Graphical circular map of the plasmid of Mesorhizobium ciceribv. biserrulae WSM1271. From outside to the center. Genes on forward strand (color by COG categories as denoted by the IMG platform), Genes on reverse strand (color by COG categories), RNA genes (tRNAs green, sRNAs red, other RNAs black), GC content, GC skew.

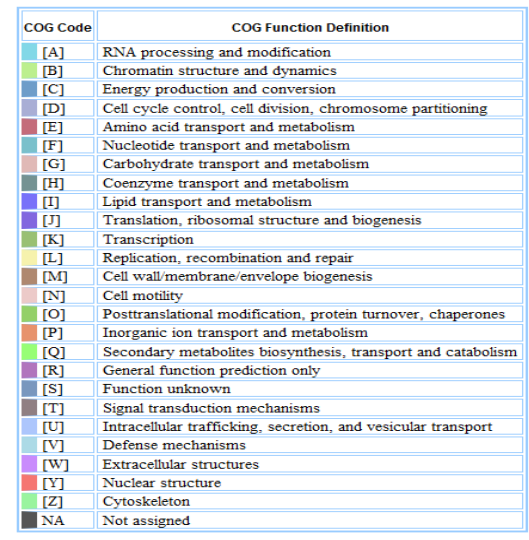

Figure 7. Color code for Figure 5 and 6. 
Table 4. Number of protein coding genes of Mesorhizobium ciceribv. biserrulae WSM $1271^{\top}$ associated with the general COG functional categ ories.

\begin{tabular}{crrl}
\hline Code & Value & \%age & COG Category \\
\hline J & 193 & 3.35 & Translation, ribosomal structure and biogenesis \\
A & 1 & 0.02 & RNA processing and modification \\
K & 492 & 8.53 & Transcription \\
L & 156 & 2.71 & Replication, recombination and repair \\
B & 6 & 0.10 & Chromatin structure and dynamics \\
D & 35 & 0.61 & Cell cycle control, mitosis and meiosis \\
Y & 0 & 0.00 & Nuclear structure \\
V & 63 & 1.09 & Defense mechanisms \\
T & 238 & 4.13 & Signal transduction mechanisms \\
M & 290 & 5.03 & Cell wall/membrane biog enesis \\
N & 62 & 1.08 & Cell motility \\
Z & 0 & 0.00 & Cytoskeleton \\
W & 2 & 0.03 & Extracellular structures \\
U & 124 & 2.15 & Intracellular trafficking and secretion \\
O & 185 & 3.21 & Posttranslational modification, protein turnover, chaperones \\
C & 356 & 6.17 & Energy production conversion \\
G & 535 & 9.28 & Carbohydrate transport and metabolism \\
E & 732 & 12.70 & Amino acid transport metabolism \\
F & 92 & 1.60 & Nucleotide transport and metabolism \\
H & 204 & 3.54 & Coenzyme transport and metabolism \\
I & 235 & 4.08 & Lipid transport and metabolism \\
P & 274 & 4.75 & Inorganic ion transport and metabolism \\
Q & 175 & 3.04 & Secondary metabolite biosynthesis, transport and catabolism \\
R & 731 & 12.68 & General function prediction only \\
S & 585 & 10.15 & Function unknown \\
\hline & 1,357 & 20.78 & Not in COGS \\
\hline & & & \\
\hline
\end{tabular}

\section{Acknowledgements}

This work was performed under the auspices of the US Department of Energy's Office of Science, Biological and Environmental Research Program, and by the University of California, Lawrence Berkeley National Laboratory under contract No. DE-AC02-05CH11231, Lawrence Livermore National Laboratory under Contract No. DEAC52-07NA27344, and Los Alamos National Laboratory under contract No. DE-AC02-06NA25396. We gratefully acknowledge the funding received from Aus tralian
Research Council Discovery grant (DP0880896), Murdoch University Strategic Research Fund through the Crop and Plant Research Institute (CaPRI) and the Centre for Rhizobium Studies (CRS) at Murdoch University. The authors would like to thank the Australia-China Joint Research Centre for Wheat Improvem ent (ACCWI) and SuperSeed Technologies (SST) for financially supporting Moham ed Ninawi's PhD project. 


\section{References}

1. O'Hara GW. The role of nitrog en fixation in crop production. J Crop Prod 1998; 1(2):115-138. http://dx.doi.org/10.1300//144v01n02 06

2. Howieson JG, Loi A, Carr SJ. Biserrula pelecinus L. - a leg ume pasture species with potential for acid, duplex soils which is nodulated by unique root-nodule bacteria. Aust J Agric Res 1995;

46:997-1009. http://dx.doi.org/10.1071/AR9950997

3. Loi A, Howieson JG, Nutt BJ, Carr SJ. A second generation of annual pasture leg umes and their potential for inclusion in Mediterranean-type farming systems. Aust J Exp Agric 2005; 45:289299. $\mathrm{http}: / / d x$. doi.org/10.1071/EA03134

4. Nandasena KG, O'Hara GW, Tiwari RP, Sezmis E, Howieson JG. In situ lateral transfer of symbiosis islands results in rapid evolution of diverse competitive strains of mesorhizobia suboptimal in symbiotic nitrogen fixation on the pasture legume Biserrula pelecinus L. Environ Microbiol 2007; 9:2496-2511. PubMed http://dx.doi.org/10.1111/j.14622920.2007.01368.x

5. Nandasena KG, O'Hara GW, Tiwari RP, Willlems A, Howieson JG. Mesorhizobium ciceri biovar biserrulae, a novel biovar nodulating the pasture leg ume Biserrula pelecinus L. Int I Syst Evol Microbiol 2007; 57:1041-1045. PubMed http://dx.doi.org/10.1099/ijs.0.64891-0

6. Nandasena KG, O'Hara GW, Tiwari RP, Willems A, Howieson JG. Mesorhizobium australicum sp. nov. and Mesorhizobium opportunistum sp. nov., isolated from Biserrula pelecinus L. in Australia. Int J Syst Evol Microbiol 2009; 59:2140-2147. PubMed http://dx.doi.org/10.1099/ijs.0.005728-0

7. Howieson JG, Ewing MA, D'antuono MF. Selection for acid tolerance in Rhizobium meliloti.

Plant Soil 1988; 105:179-188. http://dx.doi.org/10.1007/BF02376781

8. Field D, Garrity G, Gray T, Morrison N, Seleng ut J, Sterk P, Tatusova T, Thomson N, Allen M, Ang iuoli SV, et al. Towards a richer description of our complete collection of genomes and metagenomes "Minimum Information about a Genome Sequence " (MIGS) specification. Nat Biotechnol 2008; 26:541-547. PubMed http://dx.doi.org/10.1038/nbt1360

9. Woese CR, Kandler O, Wheelis ML. Towards a natural system of organisms: proposal for the domains Archaea, Bacteria, and Eucarya. Proc Natl
Acad Sci USA 1990; 87:4576-4579. PubMed http://dx.doi.org/10.1073/pnas.87.12.4576

10. Garrity GM, Bell JA, Lilburn T. Phylum XIV. Proteobacteria phyl. nov. In: Garrity GM, Brenner DJ, Krieg NR, Staley JT (eds), Berg ey's Manual of Systematic Bacteriology, Second Edition, Volume 2, Part B, Springer, New York, 2005, p. 1.

11. Validation List No. 107. List of new names and new combinations previously effectively, but not validly, published. Int I Syst Evol Microbiol 2006; 56:1-6. PubMed http://dx.doi.org/10.1099/ijs.0.64188-0

12. Garrity GM, Bell JA, Lilburn T. Class I. Alphaproteobacteria class. nov. In: Garrity GM, Brenner DJ, Krieg NR, Staley JT (eds), Bergey's Manual of Systematic Bacteriology, Second Edition, Volume 2, Part C, Springer, New York, 2005, p. 1.

13. Kuykendall LD. Order VI. Rhizobiales ord. nov. In: Garrity GM, Brenner DJ, Kreig NR, Staley JT, editors. Bergy's Manual of Systematic Bacteriology. Second ed: New York: Springer - Verlag; 2005. p 324.

14. Mergaert J, Swing s J. Family IV. Phyllobacteriaceae In: Garrity GM, Brenner DJ, Kreig NR, Staley JT, editors. Bergy's Manual of Systematic Bacteriology. Second ed: New York: Springer - Verlag; 2005. p 393.

15. Jarvis BDW, Van Berkum $\mathrm{P}$, Chen WX, Nour SM, Fernandez MP, Cleyet-Marel JC, Gillis M. Transfer of Rhizobium loti, Rhizobium huakuii, Rhizobium ciceri, Rhizobium mediterraneum, Rhizobium tianshanense to Mesorhizobium gen.nov. Int J Syst Evol Microbiol 1997; 47:895-898.

16. Chen WX, Wang ET, Kuykendall LD. The Proteobacteria. New York: Spring er - Verlag; 2005.

17. Agents B. Technical rules for biological agents. TRBA (http://www.baua.de):466.

18. Ashburner M, Ball CA, Blake JA, Botstein D, Butler $\mathrm{H}$, Cherry JM, Davis AP, Dolinski K, Dwight SS, Eppig JT, et al. Gene ontology: tool for the unification of biology. The Gene Ontology Consortium. Nat Genet 2000; 25:25-29. PubMed http://dx.doi.org/10.1038/75556

19. Kumar S, Tamura K, Nei M. MEGA3: Integ rated software for Molecular Evolutionary Genetics Analysis and sequence alignment. Brief Bio inform 2004; 5:150-163. PubMed http://dx.doi.org/10.1093/bib/5.2.150 
20. Felsenstein J. Confidence limits on phylogenies: an approach using the bootstrap. Evolution 1985; 39:783-791. http://dx.doi.org/10.2307/2408678

21. Liolios K, Mavromatis K, Tavernarakis N, Kyrpides NC. The Genomes On Line Database (GOLD) in 2007: status of genomic and metag enomic projects and their associated metadata. Nucleic Acids Res 2008; 36:D475-D479. PubMed

http://dx.doi.org/10.1093/nar/gkm884

22. Reeve WG, Tiwari RP, Worsley PS, Dilworth MJ, Glenn AR, Howieson JG. Constructs for insertional mutagenesis, transcriptional signal localization and gene regulation studies in root nodule and other bacteria. Microbiology 1999;

145:1307-1316. PubMed http://dx.doi.org/10.1099/13500872-145-6-1307

23. DOE Joint Genome Institute.

http://my.jgi.doe.gov/g eneral/index.html

24. Bennett S. Solexa Ltd. Pharmacogenomics 2004; 5:433-438. PubMed http://dx.doi.org/10.1517/14622416.5.4.433

25. Margulies $M$, Eg holm M, Altman WE, Attiya $S$, Bader JS, Bemben LA, Berka J, Braverman MS, Chen YJ, Chen Z, et al. Genome sequencing in microfabricated high-density picolitre reactors. Nature 2005; 437:376-380. PubMed

26. Zerbino DR. Using the Velvet de novo assembler for short-read sequencing technolog ies. Current Protocols in Bioinformatics 2010; Chapter 11:Unit 115.

27. Ewing B, Green P. Base-calling of automated sequencer traces using phred. II. Error probabilities. Genome Res 1998; 8:175-185. PubMed http://dx.doi.org/10.1101/gr.8.3.175

28. Ewing B, Hillier L, Wendl MC, Green P. Basecalling of automated sequencer traces using phred. I. Accuracy assessment. Genome Res 1998; 8:175-185. PubMed http://dx.doi.org/10.1101/gr.8.3.175

29. Gordon D, Abajian C, Green P. Consed: a graphical tool for sequence finishing. Genome Res 1998; 8:195-202. PubMed http://dx.doi.org/10.1101/gr.8.3.195
30. Han C, Chain P. Finishing repeat regions automatically with Dupfinisher. In: Valafar HRAH, editor. Proceeding of the 2006 international conference on bioinformatics \& computational biology: CSREA Press; 2006. p 141-146.

31. Hyatt $\mathrm{D}$, Chen $\mathrm{GL}$, Locascio PF, Land ML, Larimer FW, Hauser LJ. Prodigal: prokaryotic gene recog nition and translation initiation site identification. BMC Bioinformatics 2010; 11:119. PubMed http://dx.doi.org/10.1186/1471-2105-11-119

32. Pati A, Ivanova NN, Mikhailova N, Ovchinnikova G, Hooper SD, Lykidis A, Kypides NC. GenePRIMP: a gene prediction improvement pipeline for prokaryotic genomes. Nat Methods 2010; 7:455-457. PubMed http://dx.doi.org/10.1038/nmeth.1457

33. Lowe TM, Eddy SR. tRNAscan-SE: a prog ram for improved detection of transfer RNA genes in genomic sequence. Nucleic Acids Res 1997; 25:955-964. PubMed

34. Lagesen K, Hallin P, Rodland EA, Staerfeldt HH, Rognes T, Ussery DW. RNAmmer: consistent and rapid annotation of ribosomal RNA genes. Nucleic Acids Res 2007; 35:3100-3108. PubMed http://dx.doi.org/10.1093/nar/g km160

35. Griffiths-Jones S, Bateman A, Marshall M, Khanna A, Eddy SR. Rfam: an RNA family database. Nucleic Acids Res 2003; 31:439-441. PubMed http://dx.doi.org/10.1093/nar/g kg006

36. Krogh A, Larsson B, von Heijne G, Sonnhammer EL. Predicting transmembrane protein topology with a hidden Markov model: application to complete genomes. J Mol Biol 2001; 305:567580. PubMed http://dx.doi.org/10.1006/jmbi.2000.4315

37. Bendtsen JD, Nielsen H, von Heijne G, Brunak S. Improved prediction of sig nal peptides: SignalP 3. 0. J Mol Biol 2004; 340:783-795. PubMed http://dx.doi.org/10.1016/j.jmb.2004.05.028

38. Markowitz VM, Mavromatis K, Ivanova NN, Chen IM, Chu K, Kyrpides NC. IMG ER: a system for microbial genome annotation expert review and curation. Bioinformatics 2009; 25:2271-22 78. PubMed http://dx.doi.org/10.1093/bioinformatics/btp393 